Ana Claudia Moreira Cardoso (iD) https://orcid.org/0000-0003-3279-9411

Claudia Rejane de Lima

a Universidade Federal de Juiz de Fora (UFJF), Instituto de Ciências Humanas, Departamento de Pós-Graduação. Juiz de Fora, MG, Brasil.

b Pesquisadora autônoma. São Paulo, SP, Brasil.

Contato:

Claudia Rejane de Lima

E-mail:

claudiarelima@hotmail.com

Os autores declaram que o trabalho não foi subvencionado e que não há conflitos de interesses.

As autoras informam que o trabalho não foi apresentado em eventos científicos e que não foi baseado em dissertação ou tese.

\section{A negociação coletiva e as possibilidades de intervenção nas situações de risco à saúde no trabalho}

\author{
Collective bargaining and the possibilities \\ to intervene in health risk situations at work
}

\section{Resumo}

Introdução: neste ensaio, a negociação coletiva é vista como um processo político no qual os diferentes e desiguais atores sociais definem parâmetros para as relações de trabalho. Objetivo: discutir possibilidades e limites da negociação coletiva para modificar as situações de riscos à saúde dos trabalhadores, considerando aspectos sociais, políticos e econômicos. Métodos: analisamos a negociação coletiva no Brasil sobre a temática da saúde do trabalhador, incluindo temas como inovação tecnológica, intensidade, assédio moral organizacional e teletrabalho. Foram estudados acordos e convenções coletivas negociados entre os anos de 2010 e 2014, registrados no Sistema de Acompanhamento de Contratações Coletivas do Departamento Intersindical de Estatística e Estudos Socioeconômicos (Sacc-Dieese). Entre 2010 e 2012, tomamos por base estudos já realizados, a partir dessa mesma fonte, e para anos de 2013 e 2014, analisamos a partir de acesso direto a esse sistema. Resultados: embora tenham sido identificadas cláusulas inovadoras, grande parte das outras reproduz parâmetros previstos na legislação, com alcance limitado para modificar as condições adoecedoras. Conclusão: a aprovação da Lei $n^{0}$ 13.467/2017, aa chamada "reforma trabalhista", sob a premissa de uma relação entre “iguais”, poderá resultar na desconstrução da proteção social do trabalho e na subestimação dos riscos e do sofrimento humano.

Palavras-chave: negociação coletiva; saúde do trabalhador; condições de trabalho; acidentes de trabalho.

\begin{abstract}
Introduction: this paper accounts for collective bargaining as a political process in which differing and unequal social actors define parameters for work relations. Objective: to discuss the possibilities and limits of collective bargaining for modifying situations of workers' health risks, considering its social, political and economical aspects. Methods: we analyze collective bargaining related to workers' health in Brazil, including subjects like tecnological innovation, intensity, moral organizational harassment, and home office. We verified collective agreements negotiated between 2010 and 2014 recorded on the Sistema de Acompanhamento de Contratações Coletivas do Departamento Intersindical de Estatística e Estudos Socio-econômicos (Sacc-Dieese). Analysis of studies based on Sacc-Dieese were conducted between 2010 and 2012, whereas direct access to this system was used for the period between 2013 and 2014. Results: although innovative clauses have been found, most clauses reproduce parameters established by law, which are limited in modifying conditions that lead to sickness. Conclusion: the approval of Law No. 13.467/2017, called "Brazil Labor Reform", under the false premise of agreements between "equals", can result in the deconstruction of social protection laws and the underestimation of health risks and human suffering.
\end{abstract}

Keywords: collective bargaining; worker's health; work conditions; work accidents. 


\section{Introdução}

A negociação coletiva é um processo político no qual os diferentes e desiguais atores sociais definem condições nas quais se dará a relação entre trabalho e capital. Ela se mostra necessária considerando que essa relação, em que o trabalhador detém a força de trabalho e o capital, os meios de produção, ocorre em contexto de conflito de interesses contraditórios ${ }^{1}$, dado que o capital busca ampliar seu ganho fazendo os trabalhadores trabalharem mais por menos, e os trabalhadores, por sua vez, buscam laborar menos horas e ter um trabalho de qualidade.

De acordo com a Organização Internacional do Trabalho (OIT) ${ }^{2}$, na negociação coletiva nenhuma das partes deve impor à outra suas regras:

Cada parte escuta as proposições da outra parte e as estuda a fim de determinar se elas permitem atender e conservar o equilíbrio entre seus próprios interesses e os da outra parte na negociação [...]. Numa negociação, cada parte tem o direito de rejeitar uma proposição, de apresentar uma contra proposição ou de demandar à outra parte que faça uma concessão antes de aceitar a sua proposição. Trata-se de um processo decisional conjunto (p. 1).

Como se trata de uma relação social e historicamente determinada, além da desigualdade entre os atores sociais, há outros fatores que influenciam o processo de negociação coletiva, possibilitando ou impedindo que umas das partes se imponha à outra. A experiência política e social de uma sociedade tem papel importante nesse processo, definindo quais são as práticas aceitas ou não, o nível de influência nas decisões por parte dos trabalhadores e o significado de público e privado. No Brasil, por exemplo, a noção de que o espaço da empresa é privado é muito mais forte do que em outros países, determinando os limites da influência dos trabalhadores e também do Estado dentro do local de trabalho ${ }^{3,4}$.

O papel do Estado é essencial na definição das políticas públicas e na elaboração das leis que orientam o conteúdo e a forma da negociação coletiva, bem como na fixação de diversos direitos dos trabalhadores. Por isso mesmo a redução do papel do Estado tem mostrado seus efeitos nefastos para toda a sociedade, quando não cumpre com sua função de reduzir a desigualdade da relação entre trabalho e capital $^{5}$. Também o contexto econômico é definidor da negociação coletiva. Em momentos de crise, os trabalhadores e seus representantes têm muito mais dificuldade para ampliar os direitos, tendo de resistir para não perder o que já foi conquistado. As crises também geram um enorme contingente de trabalhadores em situação de desemprego, possibilitando que o capital se utilize do medo do desemprego para forçar os empregados a aceitarem a redução dos seus direitos ${ }^{6}$. É nesse contexto que o papel do Estado é ainda mais necessário.

A forma como o trabalho é organizado e gerido é outro determinante. Nos últimos 40 anos vivenciamos profundas mudanças no trabalho que foram influenciadas e influenciaram as transformações políticas, econômicas e sociais ${ }^{7}$. No centro dessas mudanças está a busca pela redução do chamado custo do trabalho pelo capital. A palavra de ordem tem sido a flexibilização, pensada sob um triplo aspecto: 1) flexibilidade funcional, relativa aos mecanismos organizacionais e inovações no fluxo da produção que intensificam o uso da força de trabalho (polivalência, just in time, programas de melhoria contínua etc.); e a 2) flexibilidade numérica, relativa à diversificação das formas de contratação e, por conseguinte, de demissão dos trabalhadores ${ }^{8}$; além da 3) flexibilização da remuneração.

Assim, a regulação pública e os sistemas de proteção ao trabalho seriam considerados entraves à flexibilidade necessária aos denominados "modernos" sistemas de produção, argumento que, desde os anos 1990 no Brasil, vem sendo extensamente utilizado para justificar a redução dos direitos trabalhistas ${ }^{9}$. As consequências têm sido amplamente debatidas: precarização do trabalho; aumento do desemprego; aumento do tempo de trabalho; terceirização; criação de diferentes tipos atípicos de contratação; remuneração vinculada a metas; redução da segurança no emprego; aumento dos acidentes e doenças ligadas ao trabalho, entre outros ${ }^{10-12}$.

Esta introdução nos ajuda a compreender os determinantes do processo e dos conteúdos das negociações coletivas, explicitando que seus limites não são naturais, mas sociais, políticos e econômicos. É a partir desse pressuposto que analisamos, neste ensaio, o conteúdo da negociação coletiva, no Brasil, sobre a temática da saúde do trabalhador.

Assim, o objetivo deste estudo foi analisar o que tem sido objeto de negociação sobre a temática da saúde do trabalhador, verificando as categorias profissionais que conquistaram novos direitos, destacando, ainda, os exemplos relevantes. Por outro lado, a partir do olhar sobre o que ainda não é objeto de negociação, refletir sobre suas possíveis causas, visando identificar limites e possiblidades de mudanças nas situações de trabalho adoecedoras, trazendo à reflexão as alterações instituídas no cenário atual pela chamada "reforma trabalhista”, aprovada por meio da Lei n ${ }^{0}$ 13.467/2017.

\section{Métodos}

Optamos pelo estudo dos conteúdos dos acordos e convenções coletivas, abrangendo os anos de 
2010 a 2014, baseado em três fontes complementares. Para os anos entre 2010 e 2012, utilizamos um estudo realizado por Cardoso et al. ${ }^{13}$ sobre as cláusulas relacionadas à saúde do trabalhador, e um segundo ${ }^{14}$ que discute de forma aprofundada as cláusulas sobre esse mesmo tema, mas que não estão previstas em lei. Ambos os estudos foram realizados a partir dos documentos contidos no
Sistema de Acompanhamento de Contratações Coletivas (Sacc-Dieese) ${ }^{\mathrm{C}}$. Para os anos de 2013 e 2014, atualizamos as informações pesquisando diretamente o Sacc-Dieese, sendo que os acordos relativos a esse período podem ter vigência de um ou dois anos ${ }^{\mathrm{d}}$. O Quadro 1 apresenta as informações detalhadas dos documentos referentes ao período analisado.

Quadro 1 Documentos citados no texto tendo como fonte o Sacc-Dieese

\begin{tabular}{|c|c|c|c|c|c|c|}
\hline Entidade sindical (*) & $\begin{array}{c}\text { Entidade Patronal/ } \\
\text { Empresa } \\
\text { (***) }\end{array}$ & $\begin{array}{c}\text { Tipo de } \\
\text { documento } \\
\text { (米米) }\end{array}$ & Abrangência & Vigência & Tema & Número da Cláusula \\
\hline $\begin{array}{l}\text { ST em Telecomunicações } \\
\text { de SP }\end{array}$ & $\begin{array}{l}\text { Sintesp SE Prestadoras } \\
\text { de serviços de } \\
\text { telecomunicações, } \\
\text { teleatendimento etc. }\end{array}$ & $\mathrm{CC}$ & SP & $\begin{array}{l}01 / 01 / 2013 a \\
31 / 12 / 2013\end{array}$ & Assédio moral & 30 \\
\hline $\begin{array}{l}\text { STI Vidros, Cristais e } \\
\text { Espelhos do Estado de SP }\end{array}$ & $\begin{array}{l}\text { SI Vidros e Cristais } \\
\text { Planos e Ocos do } \\
\text { estado de SP } \\
\end{array}$ & $\mathrm{CC}$ & SP & $\begin{array}{l}01 / 12 / 2014 a \\
30 / 11 / 2015\end{array}$ & Assédio moral & 66 \\
\hline $\begin{array}{l}\text { ST em Empresas de Rádio e } \\
\text { Televisão no DF }\end{array}$ & $\begin{array}{l}\text { SE de TV, Rádios, } \\
\text { Revistas e Jornais no DF }\end{array}$ & $\mathrm{CC}$ & DF & $\begin{array}{l}\text { 01/10/2014 a } \\
30 / 09 / 2016\end{array}$ & $\begin{array}{l}\text { Violência no } \\
\text { trabalho }\end{array}$ & 64 \\
\hline $\begin{array}{l}\text { Sind. dos Jornalistas } \\
\text { Profissionais do DF }\end{array}$ & $\begin{array}{l}\text { SE de TV, rádios, } \\
\text { revistas e jornais no DF }\end{array}$ & $\mathrm{CC}$ & DF & \begin{tabular}{|l|}
$01 / 04 / 2014 \mathrm{a}$ \\
$31 / 03 / 2016$ \\
\end{tabular} & $\begin{array}{l}\text { Violência no } \\
\text { trabalho }\end{array}$ & 57 \\
\hline \multirow{2}{*}{ Sind. Radialistas do RJ } & \multirow{2}{*}{$\begin{array}{l}\text { SE de Serviços/ } \\
\text { Comunicações, } \\
\text { Publicidade e } \\
\text { Empresas Jornalísticas/ } \\
\text { Rádio e TV - DF }\end{array}$} & \multirow{2}{*}{$\mathrm{CC}$} & \multirow{2}{*}{ RJ } & $\begin{array}{l}01 / 10 / 2013 a \\
30 / 09 / 2016\end{array}$ & \multirow{2}{*}{$\begin{array}{l}\text { Violência no } \\
\text { trabalho }\end{array}$} & 47 \\
\hline & & & & $\begin{array}{l}01 / 10 / 2014 \mathrm{a} \\
30 / 09 / 2016\end{array}$ & & 64 \\
\hline $\begin{array}{l}\text { STI da Construção Civil } \\
\text { do RJ }\end{array}$ & $\begin{array}{l}\text { SI Construção e do } \\
\text { Mobiliário/Construção } \\
\text { Civil - Rio de Janeiro (RJ) } \\
\end{array}$ & $\mathrm{CC}$ & RJ & $\begin{array}{l}01 / 03 / 2013 a \\
28 / 02 / 2015\end{array}$ & $\begin{array}{l}\text { Comissão de } \\
\text { saúde }\end{array}$ & 47 \\
\hline $\begin{array}{l}\text { Confederação Nacional dos } \\
\text { Trabalhadores do Ramo } \\
\text { Financeiro (Contraf) }\end{array}$ & $\begin{array}{l}\text { Fenaban - Federação } \\
\text { Nacional dos Bancos }\end{array}$ & $\mathrm{CC}$ & NA & $\begin{array}{l}01 / 09 / 2012 \mathrm{a} \\
31 / 08 / 2013\end{array}$ & $\begin{array}{l}\text { Metas/ } \\
\text { assédio moral } \\
\text { organizacional }\end{array}$ & 36 \\
\hline $\begin{array}{l}\text { ST em Telecomunicações } \\
\text { do PR }\end{array}$ & ASK - Telemarketing PR & $\mathrm{AC}$ & $\mathrm{PR}$ & $\begin{array}{l}\text { 01/01/2014 a } \\
31 / 12 / 2014\end{array}$ & Assédio moral & 21 \\
\hline $\begin{array}{l}\text { STI de Energia Elétrica } \\
\text { de Florianópolis, STI de } \\
\text { Energia Elétrica de Lages, } \\
\text { STI de Energia Elétrica do } \\
\text { Sul do Estado de SC, } \\
\text { STI de Energia Elétrica do } \\
\text { vale do Itajaí e STI Energia } \\
\text { Elétrica do Norte do Estado } \\
\text { de SC }\end{array}$ & $\begin{array}{l}\text { Celesc-Centrais } \\
\text { Elétricas de SC }\end{array}$ & $A C$ & SC & $\begin{array}{l}01 / 09 / 2014 \mathrm{a} \\
31 / 08 / 2016\end{array}$ & $\begin{array}{l}\text { Comissão } \\
\text { paritária }\end{array}$ & 37 \\
\hline $\begin{array}{l}\text { STI Metalúrgicas, Mecânicas } \\
\text { e de Material Elétrico de } \\
\text { Volta Redonda }\end{array}$ & $\begin{array}{l}\text { CSN - Companhia } \\
\text { Siderúrgica Nacional }\end{array}$ & $A C$ & $\begin{array}{l}\text { Volta } \\
\text { Redonda } \\
(\mathrm{RJ})\end{array}$ & $\begin{array}{l}01 / 05 / 2013 \text { a } \\
30 / 04 / 2014\end{array}$ & $\begin{array}{l}\text { Novas } \\
\text { tecnologias }\end{array}$ & 21 \\
\hline
\end{tabular}

(Continua)

c O Sacc-Dieese não é aberto a consulta direta. O acesso a seus dados é realizado por meio de demandas apresentadas por sindicatos e pesquisadores.

d As informações para os anos posteriores (a partir de 2015) ainda não estavam disponíveis no Sacc-Dieese no momento da elaboração deste trabalho. 
Quadro 1 Continuação...

\begin{tabular}{|c|c|c|c|c|c|c|}
\hline Entidade sindical (*) & $\begin{array}{c}\text { Entidade Patronal/ } \\
\text { Empresa } \\
\left({ }^{* * *}\right)\end{array}$ & $\begin{array}{c}\text { Tipo de } \\
\text { documento } \\
\left({ }^{* * * * * * *)}\right.\end{array}$ & Abrangência & Vigência & Tema & Número da Cláusula \\
\hline Diversos (âmbito nacional) & $\begin{array}{l}\text { CVRD - Companhia } \\
\text { Vale do Rio Doce }\end{array}$ & $\mathrm{AC}$ & NA & $\begin{array}{l}01 / 11 / 2013 \mathrm{a} \\
31 / 10 / 2015\end{array}$ & Assédio moral & 23 \\
\hline \multirow{5}{*}{$\begin{array}{l}\text { Federação Nacional } \\
\text { dos trabalhadores em } \\
\text { Correios, Telégrafos e } \\
\text { Similares, e Federação } \\
\text { Interestadual dos Sindicatos } \\
\text { dos Trabalhadores e das } \\
\text { Trabalhadoras dos Correios }\end{array}$} & \multirow{5}{*}{$\begin{array}{l}\text { ECT - Empresa } \\
\text { Brasileira de Correios e } \\
\text { Telégrafos }\end{array}$} & \multirow{5}{*}{$A C$} & \multirow{5}{*}{ NA } & \multirow{5}{*}{$\begin{array}{l}01 / 08 / 2013 \mathrm{a} \\
31 / 07 / 2015\end{array}$} & $\begin{array}{l}\text { Comissões de } \\
\text { saúde }\end{array}$ & 46 \\
\hline & & & & & $\begin{array}{l}\text { Violência } \\
\text { doméstica }\end{array}$ & 10 \\
\hline & & & & & Cipa & 31 \\
\hline & & & & & $\begin{array}{l}\text { Transtorno } \\
\text { mental }\end{array}$ & 40 \\
\hline & & & & & $\begin{array}{l}\text { Assédio moral } \\
\text { e sexual }\end{array}$ & 3 \\
\hline \multirow{2}{*}{$\begin{array}{l}\text { Federação Única dos } \\
\text { Petroleiros, STI de refinação } \\
\text { e destilação do petróleo, STI } \\
\text { de extração do petróleo e } \\
\text { STI química e petroquímica } \\
\text { do estado da Bahia. }\end{array}$} & \multirow{2}{*}{$\begin{array}{l}\text { Petrobras - Petróleo } \\
\text { Brasileiro S/A- }\end{array}$} & \multirow{2}{*}{$A C$} & \multirow{2}{*}{ NA } & \multirow{2}{*}{$\begin{array}{l}01 / 09 / 2013 \text { a } \\
31 / 08 / 2015\end{array}$} & Cipa & 122 \\
\hline & & & & & $\begin{array}{l}\text { Transtorno } \\
\text { mental }\end{array}$ & 139 \\
\hline $\begin{array}{l}\text { STE de Processamento de } \\
\text { Dados do PA }\end{array}$ & $\begin{array}{l}\text { Prodepa - Empresa } \\
\text { de Tecnologia } \\
\text { da Informação e } \\
\text { Comunicação do PR }\end{array}$ & $A C$ & PA & $\begin{array}{l}01 / 06 / 2014 \text { a } \\
31 / 05 / 2016\end{array}$ & Teletrabalho & 51 \\
\hline $\begin{array}{l}\text { Federação Trabalhadores na } \\
\text { Agricultura Estado de PE }\end{array}$ & $\begin{array}{l}\text { SI da Indústria do } \\
\text { Açúcar e do Álcool } \\
\text { de PE; Sindicado dos } \\
\text { Cultivadores de Cana } \\
\text { de Açúcar de PE } \\
\end{array}$ & $\mathrm{CC}$ & PE & $\begin{array}{l}01 / 10 / 2013 \mathrm{a} \\
30 / 09 / 2014\end{array}$ & $\begin{array}{l}\text { Novas } \\
\text { tecnologias }\end{array}$ & 78 \\
\hline $\begin{array}{l}\text { STE de Telecomunicações } \\
\text { em SC }\end{array}$ & $\begin{array}{l}\text { TIM - Telecom Itália } \\
\text { Mobile e Sul Celular }\end{array}$ & $\mathrm{AC}$ & SC & $\begin{array}{l}01 / 09 / 2014 \mathrm{a} \\
31 / 08 / 2016\end{array}$ & $\begin{array}{l}\text { Violência } \\
\text { doméstica }\end{array}$ & 25 \\
\hline $\begin{array}{l}\text { Sinergia - Sindicato dos } \\
\text { Eletricitários da Bahia }\end{array}$ & $\begin{array}{l}\text { Coelba-Companhia } \\
\text { de Eletricidade da } \\
\text { Bahia }\end{array}$ & $\mathrm{AC}$ & $\mathrm{BA}$ & $\begin{array}{l}01 / 11 / 2013 a \\
30 / 09 / 2015\end{array}$ & Cipa & 25 \\
\hline
\end{tabular}

(*) ST: Sindicato dos Trabalhadores; STI: Sindicato dos Trabalhadores na Indústria; STE: Sindicato dos Trabalhadores nas Empresas.

(***) SI: Sindicato da Indústria; SE: Sindicato das Empresas.

(****) CC: Convenção Coletiva; AC: Acordo Coletivo.

O Sacc-Dieese é um sistema desenvolvido pelo Departamento Intersindical de Estatística e de Estudos Socioeconômicos para registro das informações contidas nos documentos resultantes dos processos de negociação coletiva de trabalho (acordos coletivos, convenções coletivas e termos aditivos) e nos documentos resultantes de acordos judiciais ou julgamentos de dissídios coletivos no âmbito da Justiça do Trabalho (sentenças normativas), das principais categorias profissionais brasileiras. Em média são registradas no Sacc-Dieese cerca de 16 mil cláusulas ao ano, número que pode variar de acordo com a quantidade de documentos registrados ${ }^{14}$.

\section{A negociação coletiva como forma de intervenção na saúde do trabalhador}

Antes de analisarmos o conteúdo das negociações coletivas, vale ressaltar que elas podem se desenvolver no âmbito internacional, nacional, setorial, por categoria profissional e no local de trabalho. Além da relação de influência recíproca que se estabelece entre esses diferentes níveis, dá-se a relação direta com a legislação existente. No caso do Brasil, quando uma negociação coletiva é realizada entre entidades representantes dos trabalhadores e dos empregadores, é denominada "convenção coletiva" 
e abrange todas as empresas da base do sindicato. Quando é realizada entre entidades representantes dos trabalhadores e uma ou mais empresas, resulta num acordo coletivo. O dissídio coletivo é o processo judicial por meio do qual uma disputa trabalhista é levada à arbitragem da Justiça do Trabalho. Na maior parte dos países, a negociação coletiva tem como limite mínimo os direitos estabelecidos na legislação, impedindo que os atores sociais reduzam ou eliminem direitos já estabelecidos ${ }^{3,15}$.

Esta premissa é fundamental, levando-se em conta a desigualdade de poder entre os atores sociais, a heterogeneidade do mercado de trabalho e a fragmentação da representação sindical. Geralmente as conquistas mais significativas que superam os parâmetros legais ocorrem em setores que concentram grandes empresas e onde a organização sindical é mais forte. Nos setores mais frágeis, geralmente as negociações avançam pouco ou apenas reproduzem a legislação. Esta, por sua vez, também é a principal referência nas reivindicações e na judicialização dos conflitos. Em um país como o Brasil, onde as relações de trabalho historicamente são predatórias, onde direitos básicos são sistematicamente desrespeitados, a lei é a referência ética para assegurar alguma proteção no trabalho.

Os processos de negociação dos temas relacionados aos acidentes e adoecimento no trabalho podem ocorrer, ainda, no âmbito nas empresas, por meio da Comissão Interna de Prevenção de Acidentes (Cipa) ${ }^{\mathrm{e}}$ e de comissões de representantes de trabalhadores, a depender da força política da organização sindical nos locais de trabalho. Assim como em outras temáticas, as possibilidades de intervir nas condições de trabalho e de saúde também se realizam nas negociações estabelecidas diretamente pelos trabalhadores no seu cotidiano, sem passar pelos sindicatos ou espaços institucionalizados.

São micronegociações, praticamente invisíveis ao visitante esporádico ou menos atento. São práticas que visam o alcance de acordos - apesar da reconhecida assimetria de poder e controle - e que constroem outros modos de se realizar o trabalho, configurando-se como processos de replanejamento negociados. Elas ocorrem independente da ação política coletiva que pressuponha uma estratégia articulada, e da existência de sindicatos combativos ou de Organizações nos Locais de Trabalho - OLTs e Cipas também combati$\operatorname{vas}^{16}$ (p. 1.151).

É no cotidiano que o alcance das normas para prevenir acidentes e doenças é colocado à prova, pois é onde se confrontam o tempo todo, de um lado, a racionalidade produtiva, os resultados, objetivos e demais exigências fixadas - o que se tem que produzir -, e, de outro, as potencialidades e necessidades humanas - o que se consegue produzir, dentro das condições tecnológicas, ambientais e organizacionais estabelecidas pelo empregador ${ }^{17}$. Empregador este que geralmente desconsidera ou superdimensiona os limites físicos e psíquicos de quem executa o trabalho, além de muitas vezes negligenciar requisitos básicos de proteção à saúde ${ }^{18}$. Não é à toa que o controle do ritmo de trabalho e a revisão de metas abusivas de produção são temas recorrentes em campanhas e reivindicações de algumas categorias profissionais.

Quando os trabalhadores são forçados sistematicamente a ultrapassar seus limites, estabelece-se um campo fértil para os agravos à saúde, que aparecem de forma contundente nos acidentes de trabalho graves e fatais e nas doenças do trabalho oficialmente reconhecidas, mas também em adoecimentos que, apesar de causados pelo trabalho, são frequentemente descaracterizados ou não reconhecidos como tal (transtornos mentais, gastrites, hipertensão etc.); além de prejuízos nas relações sociais e familiares (irritabilidade, isolamento, agressividade), nem sempre evidentes aos próprios trabalhadores ou para suas famílias como decorrentes do trabalho. Os suicídios são outra expressão brutal de sofrimento no trabalho que vem crescendo e chamando atenção dos pesquisadores ${ }^{19-23}$.

No estudo realizado por Cardoso et al. ${ }^{13}$, a partir dos dados do Sacc-Dieese para o período de 2010 a 2012, os autores analisaram um amplo leque de cláusulas relacionadas à saúde do trabalhador. Dentre as cláusulas tradicionais pesquisadas estão: equipamentos de segurança e ferramentas de trabalho, uniformes, prevenção de acidentes e doenças do trabalho, exame médico, maquinário, insalubridade/ periculosidade, manutenção de máquinas e equipamentos, acidentes de trabalho, doenças do trabalho, primeiros socorros, readaptação do acidentado e/ ou portador de doença profissional, auxílio-doença, Cipa, comissões de saúde, assistência médica, estabilidade, doenças não profissionais, garantias para as mulheres, violência doméstica e garantias para trabalhadores com deficiência. No entanto não se limitaram apenas a aquelas tradicionalmente classificadas como tal, abrangendo a questão da inovação tecnológica, do ritmo de trabalho, da intensidade, da participação dos trabalhadores e do acesso à informação. Do total de cláusulas registradas sobre todos os temas (46.806 cláusulas), aproximadamente $20 \%$

e Conforme a Portaria $\mathrm{n}^{\circ}$ 3214/1978 do Ministério do Trabalho, a Comissão Interna de Prevenção de Acidentes (Cipa) - estabelecida por meio da Norma Regulamentadora $\mathrm{n}^{\circ} 5$ (NR 5) - é formada paritariamente por representantes dos empregados e empregadores com o objetivo a prevenir acidentes e doenças no trabalho. 
(9.492 cláusulas) se referia a questões relativas à saúde do trabalhador.

Nos anos de 2013 e 2014, foi registrado o total de 25.598 cláusulas no Sacc-Dieese, sendo que, destas, 4.889 tinham como palavra-chave "saúde do trabalhador". Foram analisadas, sobretudo, aquelas cláusulas que inovavam ao definir regras para a relação entre a saúde do trabalhador e a organização do trabalho, como as relacionadas com inovação tecnológica, intensidade, assédio moral/organizacional, violência e estresse no trabalho, teletrabalho, entre outras.

Tal informação poderia significar algo positivo não fosse o fato de o conteúdo dessas cláusulas ser muito limitado. Dentre as 9.492 cláusulas, a maior parte se refere a questões básicas, muitas vezes previstas em lei e que focalizam condições ambientais do trabalho, como adequação de mobiliário, Equipamento de Proteção Individual (EPI), uniforme e outras. Os adicionais de insalubridade e de periculosidade também aparecem em grande quantidade, mas sem problematizar a monetização dos riscos e sem demandar sua substituição por investimentos efetivos para eliminá-los, repetindo o que está previsto em lei ${ }^{13}$.

No estudo realizado por Cardoso e Morgado ${ }^{14}$, que também teve como base o Sacc-Dieese, entre os anos de 2010 e 2012, as autoras analisaram cláusulas sobre temas relacionados à saúde dos trabalhadores que não estão previstos em lei, como: inovações tecnológicas e organizacionais, intensidade do trabalho, ritmo de trabalho, assédio moral organizacional, saúde mental, dependência e estresse no trabalho. As autoras afirmam que as cláusulas que tratam dessas questões são poucas e muitas vezes aparecem desarticuladas das demais questões presentes nos acordos e convenções, não relacionando as causas dos adoecimentos com a organização do trabalho, muito menos estabelecem relações de trabalho que respeitem a especificidade de cada trabalhador.

Dentre as cláusulas interessantes relativas ao tema da "inovação tecnológica", há alguns documentos que preveem a consulta e/ou discussão com o sindicato dos trabalhadores quando da implantação de processo de inovação tecnológica ${ }^{13}$. Por exemplo, o acordo coletivo realizado com a Petrobras (vigência entre 01/09/2011 e 31/08/2013), a convenção coletiva dos Jornalistas do Ceará (vigência entre 01/09/2012 e $31 / 08 / 2013)^{7}$, o acordo com a Companhia Siderúrgica Nacional (CSN) (vigência entre 01/05/2013 e 30/04/2014) e a convenção dos trabalhadores rurais de PE (vigência entre 01/10/2013 e 30/09/2014). Para os anos de 2013 e 2014, as outras três cláusulas encontradas tratam da formação para que os trabalhadores possam utilizar a inovação implantada. Pode-se observar, assim, a inexistência de cláusulas que definam a discussão dos impactos da inovação no cotidiano de trabalho, sobretudo no que se refere à intensificação e à saúde dos trabalhadores.

Em relação à "intensidade e ritmo de trabalho", Cardoso et al. ${ }^{13}$ ressaltam que foram encontradas apenas duas cláusulas no período entre 2010 e 2012, que se limitavam a reproduzir as recomendações contidas na Norma Regulamentadora $\mathrm{n}^{\mathrm{o}} 17^{\mathrm{f}}$ e a recomendar mudanças na organização física do trabalho. Considerando que um dos problemas decorrentes do aumento da intensidade é que ela torna difícil a adoção de práticas indispensáveis para a preservação da saúde, como "mudar de posição, respirar, organizar o posto de trabalho, escolher o instrumento adaptado, se informar corretamente, buscar a cooperação, antecipar para evitar ou se preparar para as situações de urgência" ${ }^{24}$ (p. 1), as fortes pressões do ritmo têm sido "associadas a uma percepção mais pessimista da relação entre trabalho e saúde"25 (p. 1).

Uma experiência interessante de enfrentamento da intensificação do trabalho foi a campanha Menos Metas, Mais Saúde ${ }^{26}$, lançada em 2010 pela Confederação Nacional dos Trabalhadores no Setor Financeiro da Central Única dos Trabalhadores (Contraf-CUT) e pelo Sindicato dos Bancários de São Paulo, problematizando as metas de produção abusivas fixadas pelos bancos e o assédio moral organizacional como mecanismos de gestão de resultados. A campanha foi inovadora por transformar a organização do trabalho e seus mecanismos de controle derivados em objeto de negociação com os empregadores. Fruto dessa campanha foram conquistados na convenção coletiva nacional dos bancários (vigência entre 2013 e 2014), na cláusula $36^{\text {a }}$, que determina: "No monitoramento de resultados, os bancos não exporão, publicamente, o ranking individual de seus empregados" (p.14), e proibindo a "cobrança de cumprimento de resultados por torpedos (SMS), pelo gestor, no telefone particular do empregado"27 (p. 14).

Outro tema analisado foi o do assédio moral organizacional, considerando que, de acordo com Seligmann-Silva ${ }^{28}$, algumas das patologias relacionadas à violência laboral podem ter como ponto de partida o sofrimento e o desgaste produzidos por esse tipo de assédio ${ }^{29}$. Sendo que, quando os episódios se repetem, podem vir a desencadear transtornos mentais graves, podendo, inclusive, levar ao suicídio da vítima. Apesar da importância, constatamos que essa questão está pouco presente nas negociações do período entre 2010 e 2014 e, quando tratada, fica

f Conforme a Portaria $n^{\circ} 3.214 / 1978$, do Ministério do Trabalho (NR 17), Ergonomia é a Norma Regulamentadora que define parâmetros para adaptação das condições de trabalho às características psicofisiológicas dos trabalhadores. 
restrita à relação entre os gerentes e os trabalhadores, não se considerando o assédio moral organizacional como um instrumento de gestão, relacionado às metas ou à organização do trabalho.

Entretanto, considerando que mesmo diante de um problema de tal amplitude ainda não há uma legislação sobre o assunto, as poucas cláusulas encontradas demonstram que é possível e necessário incluir essa questão nas negociações. Diante de relações de trabalho ainda marcadas pelo extremo autoritarismo, discriminação, ameaças, intimidações e humilhações, é importante a presença de cláusulas que coíbam tais atitudes, como a presente na convenção coletiva dos trabalhadores nas empresas de vidro do estado de São Paulo (vigência entre 01/12/2014 e 30/11/2015), dos trabalhadores do setor de telemarketing do estado de São Paulo (vigência entre 01/01/2013 e 31/12/2013), e os acordos com a empresa Vale do Rio Doce (vigência entre 01/11/2013 e 31/10/2015) e da empresa de telefonia ASK do estado do Paraná (vigência entre 01/01/2014 e 31/12/2014). Uma das cláusulas mais completas foi negociada pelos trabalhadores do setor de plástico do estado da Bahia (vigência entre 01/11/2012 e 31/10/2013), prevendo que:

\begin{abstract}
As empresas não adotarão quaisquer práticas gerenciais e de organização de trabalho que possam caracterizar assédio moral aos seus empregados, entendidas como tais todas as formas de constrangimento, intimidação, humilhação e discriminação perpetrados em face dos seus empregados, desde que decorrentes da relação de trabalho, e de que possam resultar sofrimento psicológico para os mesmos com reflexos na saúde física, mental e moral. As empresas ratificam seus compromissos em cumprimento da legislação relativa a quaisquer discriminações relativas a sexo, idade, cor, religião, estado civil, etnia, número de filhos, tanto para admissão como para preenchimentos de $\operatorname{cargos}^{7}$ (p. 15).
\end{abstract}

Em relação ao tema da "violência no trabalho”, encontramos algumas cláusulas negociadas pelos jornalistas do DF (vigência entre 01/04/2014 e 31/03/2016), radialistas do DF (vigência entre 01/10/2014 e 30/09/2016) e pelos radialistas do RJ (vigência entre 01/10/2013 e 30/09/2014), prevendo ações em relação à violência e segurança no trabalho desses profissionais que trabalham nas ruas. Esse tema também está presente em cláusulas relativas ao espaço fora do local de trabalho, referindo-se à “violência doméstica”, como podemos ver no acordo com a empresa TIM Sul Celular do Paraná (vigência entre 01/09/2014 a 31/08/2016), em que foi negociada uma licença de até três dias para as trabalhadoras vítimas de violência doméstica. No caso do acordo feito pelos correios (vigência entre 01/08/2013 e $31 / 07 / 2015$ ), a cláusula prevê prioridade na transferência de unidade para as trabalhadoras vítimas de violência doméstica, além da implantação de comissões regionais que terão como objetivo identificar os casos de violência doméstica e violação de direitos humanos nos locais de trabalho.

Quando analisamos o tema do estresse no trabalho ${ }^{13}$, encontramos uma única cláusula definindo apenas mudanças no ambiente físico de trabalho. Na Europa, em 2004, foi assinado um acordo ${ }^{30}$ sobre essa temática e, a partir dele, diversas entidades sindicais na Dinamarca, na França e na Alemanha criaram campanhas em torno do tema e o incluíram em suas negociações coletivas. Na Suécia, a central sindical criou, inclusive, um "barômetro do estresse"29, demonstrando a importância de leis que levam os atores sociais a discutirem determinado problema.

Para o período entre 2010 e 2014, ao pesquisarmos o tema da "qualidade no trabalho", encontramos uma cláusula intitulada "qualidade de vida no trabalho”, que dispõe sobre práticas e programas que estimulam hábitos saudáveis nos trabalhadores, deixando totalmente de lado a dimensão coletiva e social do trabalho, focando unicamente no aspecto individual $^{13}$. Por outro lado, em diversos países da Europa Ocidental é possível observar muitas campanhas e programas sindicais sobre "equilíbrio entre vida e trabalho”. É o caso de várias convenções coletivas realizadas na Áustria, na Suécia e na Bélgica ${ }^{31}$. Na Alemanha, o Ver.dig lançou, em 2003, uma campanha com o slogan "tenha tempo para você", e o IG Metalh tem enfatizado a questão do "bom emprego" 31 . Nesses casos, o foco da qualidade sai do indivíduo e se coloca no centro da relação entre trabalho e vida privada, fazendo um contraponto à crescente flexibilização do tempo de trabalho.

Também realizamos uma pesquisa com a palavra-chave “comissões de saúde” e vimos que não há muitas cláusulas sobre essa temática. No acordo com os Correios (vigência entre 01/08/2013 e 31/07/2015), estava prevista a instalação de mesas temáticas sobre horas-extras, condições de trabalho, saúde do

g Ver.di - Vereinte Dienstleistungs-Gewerkschaft (Sindicato Unificado dos Trabalhadores em Serviço), representa os trabalhadores alemães do setor de serviços, incluindo as áreas de educação, arte e cultura, meios de comunicação e bancos. Filiado à DGB Central Deutscher Gewerkschaftsbund (Confederação Alemã dos Sindicatos), o Ver.di é o segundo maior sindicato na Alemanha e na Europa. Disponível em: https://www.verdi.de/. Acesso em: 6 ago. 2018.

h O sindicato alemão IG Metal - Industriegewerkschaft Metall (Sindicato da Indústria de Metal) representa os trabalhadores na indústria de metalúrgica, têxtil e vestuário, madeira e plásticos. O IG Metal é o maior sindicato na Alemanha e na Europa, e é filiado à DGB. Disponível em: https://www.igmetall.de/. Acesso em: 6 ago. 2018. 
trabalhador, questão da mulher, de gênero e racial. Já no acordo feito entre os eletricitários de Santa Catarina e as Centrais Elétricas de Santa Catarina Celesc (vigência entre 2013 e 2015), foi negociada a constituição de uma comissão paritária para analisar e deliberar sobre temas relacionados à saúde do trabalhador, assim como no acordo coletivo com a Caixa Econômica Federal (vigência entre 01/09/2014 e 31/08/2015). Finalmente, na Convenção Coletiva dos Trabalhadores da Construção Civil do Rio de Janeiro (vigência entre 01/03/2013 a 28/02/2015), criou-se uma comissão permanente para vistoriar sistematicamente os canteiros de obras e apresentar às empresas laudos orientativos, composta de técnicos, representantes dos sindicatos dos trabalhadores e das empresas. Não por coincidência, dos quatro documentos analisados, três foram negociados com empresas estatais que, historicamente, têm sido palco de um processo de negociação coletiva muito mais amplo, reforçando o que já discuti$\operatorname{mos}^{15}$, de que as empresas privadas entendem que os trabalhadores, os sindicatos e mesmo o Estado não podem intervir na definição da organização e da gestão do trabalho.

Ainda no que se refere ao tema das comissões, vemos que a $\mathrm{Cipa}^{32}$ aparece nos períodos estudados como principal referência para os assuntos relativos à saúde dos trabalhadores. A realização das eleições, liberação dos seus membros para os treinamentos e para o trabalho de prevenção durante a jornada de trabalho são os temas mais presentes nos acordos, ora reiterando as determinações da Norma Regulamentadora $\mathrm{n}^{0} 5$ (NR 5$)^{33}$ ora detalhando condições para o seu cumprimento. Esse é o caso da cláusula 31 do acordo dos Correios (vigência entre 01/08/2014 e 31/07/2015), que detalha o número de horas para a realização do trabalho; da cláusula 122 da Petrobras (vigência entre 01/09/2013 e 31/08/2015), que assegura o acesso aos dados estatísticos. Fora das atribuições da NR 5, no acordo citado da Petrobras está prevista a realização de encontro anual dos membros da Cipa da própria empresa e das contratadas; e o acordo da Companhia de Eletricidade da Bahia (Coelba) (vigência entre 01/11/2013 a 30/09/2015) atribui à Cipa o papel de fiscalizar as condições de trabalho das empresas contratadas.

Os transtornos mentais relacionados ao trabalho representam um problema de proporções consideráveis, dada sua alta prevalência e diversidade de categorias atingidas em função das novas formas de organizar o trabalho ${ }^{34}$. No Sacc-Dieese, para o período entre 2010 e 2014, essa questão foi tratada em apenas três instrumentos normativos. Nos acordos do Metrô de São Paulo (vigência entre 01/05/2012 e 30/04/2013) e dos trabalhadores dos
Correios (vigência entre 01/08/2012 e 31/07/2013), está prevista a assistência psicológica nos casos em que os trabalhadores são vítimas de assalto, mas desconsideram "outros eventos laborais que impactam a saúde mental" 7 (p. 150). No acordo com a Petrobras (vigência entre 01/09/2013 e 31/08/2015), o tema é tratado de forma mais ampla, definindo-se que a empresa se comprometerá "a estruturar o Programa de Saúde Mental com foco em ações individuais, coletivas e no ambiente de trabalho como ação de saúde integral para a melhoria das condições de saúde dos empregados, em atendimento aos requisitos legais".

Finalmente encontramos uma cláusula sobre teletrabalho, no acordo com a Empresa de Tecnologia, Comunicação e Informação do Pará (Prodepa) (vigência entre 01/06/2014 e 31/05/2016), prevendo que a empresa deve realizar "estudos para normatizar e viabilizar projeto piloto sobre o teletrabalho". Na chamada "reforma trabalhista" ${ }^{35}$, os teletrabalhadores ficaram sem garantias em relação ao ambiente de trabalho, às condições de trabalho, à jornada normal e extraordinária e aos intervalos, entre outras. A Lei $\mathrm{n}^{\circ} 13.467 / 2017$ exclui o teletrabalho do artigo 62 da Consolidação das Leis do Trabalho (CLT), que regulamenta a jornada de trabalho; define genericamente, sem estabelecer a responsabilidade do empregador, que os equipamentos e reembolso de despesas arcadas pelo empregado serão previstas em contrato escrito; e limita-se a dizer no seu artigo 75-E que "empregador deverá instruir os empregados, de maneira expressa e ostensiva, quanto às precauções a tomar a fim de evitar doenças e acidentes de trabalho" 36 .

Uma legislação que, em vez de garantir direitos, os retira. No âmbito internacional, há várias legislações sobre o assunto, como a regulamentação da OIT $\mathrm{n}^{\mathrm{o}} 177^{36}$, não ratificada pelo Brasil, além do acordo europeu sobre o teletrabalho, negociado em $2002^{37}$. São regras que explicitam que os trabalhadores em domicílio e os teletrabalhadores têm direito à mesma proteção jurídica que os outros, ficando sob a mesma legislação e a mesma negociação coletiva, enfatizando a igualdade de tratamento no que se refere às condições de trabalho, à jornada de trabalho e à remuneração ${ }^{38}$.

\section{Considerações finais}

A intervenção nas situações de risco e sofrimento implica em considerar não só as condições de trabalho (físicas, químicas, biológicas) que incidem principalmente no corpo dos trabalhadores e sobre as quais há um extenso acúmulo sintetizado em normas legais, como é fundamental levar em conta outras dimensões como sua organização, gestão, além das 
relações que se desenvolvem no ambiente de trabalho - aspectos de enfrentamento mais complexo por remeter fundamentalmente às regras que definem as relações de poder.

Evidentemente, cláusulas sobre direitos básicos e focados nas condições ambientais de trabalho são importantes, assim como o cumprimento da lei no tocante à reparação dos danos causados pelo trabalho, mas a questão é que elas não modificam as condições técnicas e organizacionais que causam acidentes e doenças. Ficam de lado questões determinantes no processo de adoecimento, como a gestão por metas, o assédio moral organizacional, a intensificação, os processos de inovação técnico-organizacionais, a falta de autonomia do trabalhador, os processos de avaliação, o estresse no trabalho, a falta de acesso à informação e de participação do trabalhador ${ }^{39,40}$.

No período analisado, 2010-2014, a reiteração da lei permanece como o principal conteúdo pactuado, em alguns casos até no que refere a direitos muito básicos, cuja falta fere o princípio da dignidade humana, como o fornecimento de água potável, de papel higiênico e de sabão. Se para algumas categorias profissionais condições mínimas de conforto e higiene ainda compõem a pauta, as expectativas de conquistar direitos acima do que está previsto na legislação ou que modifiquem as condições técnicas e organizacionais do trabalho pode parecer uma utopia.

O paradoxo no contexto atual, após a aprovação da "reforma trabalhista", é que a reprodução das normas de proteção à saúde previstas em lei poderá significar um avanço, diante da primazia do negociado sobre o legislado, em que padrões rebaixados de direitos poderão ser pactuados de forma individual e coletiva, além do trabalho intermitente e outras mudanças que institucionalizam a contratação precarizada. A liberação irrestrita da terceirização ${ }^{\mathrm{i}}$ e a modificação dos parâmetros de classificação do trabalho escravo se somam ao conjunto de estratégias de profunda desconstrução da proteção social do trabalho e de banalização dos riscos e do sofrimento humano.

Para os defensores da "reforma trabalhista", as leis são "uma excrescência, um anacronismo que 'engessa' o mercado de trabalho porque impõem limites à livre contratação de trabalhadores" 41 (p. 18). Segundo essa visão, a regulação estatal deve dar lugar à negociação coletiva entre as partes, descentralizando-a se possível até o âmbito da empresa, sob a premissa de que a relação de trabalho seria um contrato entre "iguais", isto é, desconsiderando as assimetrias de poder entre capital e trabalho, que são o pano de fundo do Direito do Trabalho e todo o sistema de proteção dos trabalhadores ${ }^{41}$.

Ao enfraquecer a regulação pública do trabalho, a "reforma trabalhista" aponta para a "quebra do contrato civilizatório que permite que a sociedade funcione minimamente equilibrada" 42 , conforme aponta nota dos profissionais da Fundacentro, manifestando preocupações com seus impactos em relação à proteção da saúde dos trabalhadores. Estão em jogo não só os parâmetros para a contratação do trabalho, como para a inspeção e fiscalização e o acesso à Justiça do Trabalho.

Se sob a vigência de normas a realidade do trabalho tem se mostrado perversa no que diz respeito à proteção da saúde dos trabalhadores, pode-se imaginar o quanto o "salve-se quem puder" instituído pela "reforma trabalhista" poderá repercutir nas doenças e nos acidentes causados pelo trabalho, considerando que a pressão das necessidades imediatas da sobrevivência coloca a saúde em segundo plano, sobretudo nos contextos de crise e de desemprego. Não se trata de fazer uma defesa ingênua das leis, em particular das de saúde e segurança no trabalho, cujos limites não são poucos e demandariam um artigo específico para discuti-los. O problema é que, nos termos colocados pela "reforma trabalhista", a negociação coletiva é o principal instrumento para legitimar a visão de alguns empresários e políticos de que é melhor ter um emprego com poucos direitos do que não ter emprego nenhum e, assim, vão minguando as perspectivas de conquistar melhores condições de vida e de trabalho.

Se antes da "reforma trabalhista" era um desafio para o movimento sindical negociar a partir das demandas geradas cotidianamente no trabalho, diminuindo o fosso entre o que é exigido dos trabalhadores e as possibilidades reais de sua efetivação, no contexto atual o desafio de olhar o cotidiano do trabalho não só se atualiza como é um requisito para elaborar estratégias de resistência e para a construção de um campo de forças mais favorável para os trabalhadores.

i A liberação irrestrita da terceirização foi feita por meio da Lei no 13 429/2017. Até então, a única referência legal era a Súmula 331 do Tribunal Superior do Trabalho (TST), que, apesar de insuficiente para conter seu crescimento, a restringia às atividades-meio, assegurando alguma salvaguarda legal de proteção aos trabalhadores. Vale dizer que a regulamentação da terceirização foi alvo de intensa disputa no Congresso Nacional ${ }^{12}$, mas, a despeito das ações de resistência das centrais sindicais, sindicatos de trabalhadores, juristas, pesquisadores e outros segmentos contrários à precarização do trabalho, que inclusive apresentaram alternativas de regulamentação, a lei aprovada teve por base o Projeto de Lei $\mathrm{n}^{\circ} 4302$ que tramitava desde 1998 e tinha amplo apoio dos segmentos empresariais representados no Congresso. 


\section{Contribuição de autoria}

As autoras contribuíram igualmente na concepção do projeto, análise das informações, elaboração do manuscrito, revisão crítica e na aprovação final da versão publicada. As autoras assumem integral responsabilidade pelo trabalho publicado e seu conteúdo.

\section{Referências}

1. Marx K. O capital. 12a ed. São Paulo: Bertand Brasil; 1985. v. 1.

2. Bureau International du Travail. Thèmes de négociation collective: fiche d'information $\mathrm{n}^{\mathrm{o}} 3$ [Internet]. Geneva, Nov. 2016 [cited 10 Nov 2019]. Available from: http://www.ilo.org/wcmsp5/groups/ public/---ed_protect/---protrav/---travail/documents/ publication/wcms_538185.pdf

3. Bernaciak M, Gumbrell-McCormick R, Hyman R. Syndicalisme européen: de la crise au renouveau? Bruxelles: European Trade Union Institute, 2015. Rapport 133.

4. Cardoso ACM. Organização e intensificação do tempo de trabalho. Soc Est. 2013;28:351-74.

5. Filgueiras MAL. Reestruturação produtiva, globalização e neoliberalismo: capitalismo e exclusão social neste final de século. Anais do $5^{\circ}$ Encontro Nacional da Associação Brasileira de Estudos do Trabalho; 1997; São Paulo. Salvador: Universidade Federal da Bahia; 1997.

6. Cochard M, Cornilleau G, Heyer E. Les marchés du travail dans la crise. Econom Stat. 2010; (438-440):181-204.

7. Boltanski L, Chiapello E. Le nouvel esprit du capitalisme. Paris: Gallimard; 1999.

8. Smith V. New forms of work organization. Annu Rev Psychol. 1996;47:307-38.

9. Krein KJ, Biavaschi BM. Brasil: os movimentos contraditórios da regulação do trabalho dos anos 2000. CDC [Internet]. 2015;32(89):47-82 [citado em 10 nov 2019]. Disponível em: http:ve.scielo. org/scielo.php?script = sci_arttext\&pid=S101225082015000200004\&Ing $=$ es\&nrm $=$ iso

10. Antunes R. Os sentidos do trabalho: ensaio sobre a afirmação e a negação do trabalho. 4a ed. São Paulo: Boitempo; 2001.

11. Druck MG. Flexibilização, terceirização e precarização: formas contemporâneas de dominação do trabalho. Cad CRH [Internet]. 2002;(37):11-22 [citado em 10 nov 2019]. Disponível em: www.flexibilizacao.ufba.br/RCRH2006-270graca.pdf

12. Conceição JJC, Lima CR. Empresários e trabalhadores diante da regulamentação da terceirização: é possível um acordo mínimo? In: Dau DM, Conceição JJ. Terceirização no Brasil: do discurso da inovação à precarização do trabalho (atualização do debate e perspectivas). São Paulo: Annablume; 2009. p. 187-211.
13. Cardoso ACM, Ribeiro D, Morgado LP, Linhares R. A saúde do trabalhador no processo de negociação coletiva no Brasil. Estudos e pesquisas, n. 76. São Paulo: Dieese; 2015.

14. Cardoso, ACM, Morgado LP. Saúde do trabalhador no processo de negociação coletiva: a necessidade de inclusão de questões determinantes do processo saúde-doença. Rev Cienc Trab. 2015;(4):7-26.

15. Departamento Intersindical de Estatística e Estudos Socioeconômicos. Estrutura e processo de negociação coletiva. Caderno do Formador e Participante. Coleção Seminários de Negociação. São Paulo; 2004.

16. Sato L. Prevenção de agravos à saúde do trabalhador: replanejando o trabalho através das negociações cotidianas. Cad Saude Pub [Internet]. 2002;18(5):1147-57 [citado em 10 nov 2019]. Disponível em: http://dx.doi.org/10.1590/S0102311X2002000500002

17. Gollac M, Bodier M. Mesurer les facteurs psychosociaux de risque au travail pour les maîtriser. Rapport du Collège d'expertise sur le suivi des risques psychosociaux au travail. Paris: Ministère du Travail; 2011.

18. Lima CR. Hora extra e saúde no contexto da produção enxuta. In: Central Única dos Trabalhadores. Hora extra: o que a CUT tem a dizer sobre isto. São Paulo: CUT; 2006. p. 89-95.

19. Dejours C. Conjurer la violence: travail, violence et santé. Paris: Éditions Payot \& Rivages; 2007.

20. Dejours C. Por um novo conceito de saúde. Rev Bras Saude Ocup. 1986;14(54):7-11.

21. Guerin F, Laville A, Daniellou. Compreender o trabalho para transformá-lo: a prática da ergonomia. São Paulo: Blucher; 2001.

22. Sato L. Abordagem psicossocial do trabalho penoso: estudo de caso de motoristas de ônibus urbano [dissertação]. São Paulo: Pontifícia Universidade Católica de São Paulo; 1991. 107 p.

23. Dejours C. Suicídio e trabalho: o que fazer? Distrito Federal: Paralelo 15; 2010.

24. Boisard P, Cartron D, Gollac M, Valeyre A. Temps et travail: l'intensité du travail. Luxembourg: Fondation Européenne pour l'Amélioration des Conditions de Vie et de Travail; 2002.

25. Boisard P, Cartron D, Gollac M, Valeyre A. Contraintes de temps dans le travail et risques pour la santé en Europe. Quat Pag. 2011(47):1-4. 
26. Confederação dos Trabalhadores do Ramo Financeiro da CUT. Lançada campanha "Menos Metas, Mais Saúde" em seminário sobre assédio moral [Internet]. São Paulo: Contraf; 2010 [citado em 10 nov 2019]. Disponível em: https://contrafcut. com.br/noticias/lancada-campanha-menosmetas-mais-saude-em-seminario-sobre-assediomoral-1261/

27. Confederação dos Trabalhadores do Ramo Financeiro da CUT. Convenção coletiva de trabalho 2013/2014 [Internet]. São Paulo: Contraf; 2014 [citado em 10 nov 2019]. Disponível em: https://portal.febraban.org.br/pagina/3104/74/pt-br/ convencao-coletiva-trabalho-2013

28. Seligmann-Silva E. Trabalho e desgaste mental: o direito de ser dono de si mesmo. São Paulo: Cortez; 2011.

29. União Europeia. Acordo-quadro europeu sobre assédio e violência no trabalho, 2007 [Internet]. Bruxelas; 2007 [citado em 10 nov 2019]. Disponível em: https://eur-lex.europa.eu/LexUriServ/ LexUriServ.do?uri=COM:2007:0686:FIN:PT:PDF

30. European Union. Framework agreement on workrelated stress [Internet]. Brussels; 2004 [cited 10 Nov 2019]. Available from: http://erc-online.eu/wp-content/ uploads/2014/04/2005-00679-EN.pdf

31. Bernaciak M, Gumbrell-McCormick, Hyman R. Syndicalisme européen: de la crise au renouveau? Rapport 133. Bruxelles: European Trade Union Institute; 2015.

32. Brasil. Escola Nacional da Inspeção do Trabalho. SST - Normatização [Internet]. Brasília, DF [citado em 10 nov 2019]. Disponível em: https:/enit.trabalho.gov.br/portal/index.php/ seguranca-e-saude-no-trabalho/sst-menu/sstnormatizacao?view $=$ default

33. 33. Brasil. Ministério do Trabalho e Emprego. NR 05 - Comissão Interna de Prevenção de Acidentes [Internet]. Brasília: Ministério do Trabalho e Emprego [citado em 10 nov 2019]. Disponível em: http://trabalho.gov.br/images/Documentos/SST/ NR/NR5.pdf

34. Maeno M, Pararelli R. O trabalho como ele é e a saúde mental do trabalhador. In: Silveira MA, organizador. Inovação para o desenvolvimento de organizações sustentáveis: trabalho, fatores psicossociais e ambiente saudável. Campinas: Centro de Tecnologia da Informação Renato Archer; 2013. p. 145-66.

35. Brasil. Lei $\mathrm{n}^{\mathrm{o}}$ 13.467, de 13 de julho de 2017. Altera a Consolidação das Leis do Trabalho (CLT), aprovada pelo Decreto-Lei $\mathrm{n}^{0} 5.452$, de $1^{\circ}$ de maio de 1943, e as Leis $\mathrm{n}^{\circ}$ 6.019, de 3 de janeiro de 1974, 8.036, de 11 de maio de 1990, e 8.212, de 24 de julho de 1991, a fim de adequar a legislação às novas relações de trabalho. Diário Oficial da União [Internet]. 14 jul. 2017 [citado em 14 ago 2018]. Disponível em: http://www.planalto.gov.br/ ccivil_03/_ato2015-2018/2017/lei/L13467.htm

36. Organización Internacional del Trabajo. Convenio sobre el trabajo a domicilio [Internet]. Ginebra; 1996 [citado en 14 ago 2018]. Disponible en: http:// www.ilo.org/dyn/normlex/es/f?p=NORMLEXPUB:1 2100:0::NO::P12100_INSTRUMENT_ID:312322

37. Organisation Internationale du Travail. Accordcadre sur le télétravail [Internet]. Genève; 2002 [cited 2018 Ago 14]. Available from: http:// erc-online.eu/wp-content/uploads/2014/04/200701004-EN.pdf

38. Popma J. Technostress et autres revers du travail nomade. Working Paper 7. Bruxelles: European Trade Union Institute; 2013.

39. Cardoso ACM. Organização e intensificação do tempo de trabalho. Soc Est. 2013;28:351-374.

40. Alves G. Trabalho e subjetividade: o espírito do toyotismo na era do capitalismo manipulatório. São Paulo: Boitempo; 2011.

41. Galvão A, Krein JD, Biavaschi MB, Teixeira, MO. Dossiê "reforma" trabalhista (em construção). Campinas: Unicamp; 2017.

42. Comissão de Representação dos Servidores da Fundacentro. Servidores da Fundacentro emitem nota sobre a Reforma Trabalhista. Revista Proteção [Internet]. 1 set. 2018 [citado em $18 \mathrm{dez}$. 2017]. Disponível em: http://www.protecao.com. br/noticias/geral/servidores_da_fundacentro emitem_nota_sobre_a_reforma trabalhista_/ JyyJAAjbA5/11694 